\title{
Exploring the challenges for clinical pharmacists in Sudan
}

\author{
Elsadig, Hwaida
}

2017

Elsadig , H , Weiss , M , Scott , J \& Laaksonen , R 2017 , ' Exploring the challenges for clinical pharmacists in Sudan ', International Journal of Clinical Pharmacy, vol. 39 , no. 5 , pp. 1047-1054 . https://doi.org/10.1007/s11096-017-0521-8

http://hdl.handle.net/10138/298047

https://doi.org/10.1007/s11096-017-0521-8

publishedVersion

Downloaded from Helda, University of Helsinki institutional repository.

This is an electronic reprint of the original article.

This reprint may differ from the original in pagination and typographic detail.

Please cite the original version. 


\title{
Exploring the challenges for clinical pharmacists in Sudan
}

\author{
Hwaida Elsadig $^{1}$ (1) $\cdot$ Marjorie Weiss $^{2} \cdot$ Jenny $^{S \operatorname{Sott}^{1}} \cdot$ Raisa Laaksonen $^{3}$
}

Received: 17 February 2017/ Accepted: 2 August 2017/Published online: 19 August 2017

(c) Springer International Publishing AG 2017

\begin{abstract}
Background Clinical pharmacy practice in hospitals is a new role for pharmacists in Sudan. Pharmacists have to face the challenge of moving from their traditional roles within the pharmacy premises to new roles on the wards with direct contact with patients and other healthcare professionals. Objectives To explore the role and challenges facing the clinical pharmacists of Sudan. Settings Two of the main government hospitals in Sudan and an online survey. Method This study applied a two phase mixed method, a focus group discussion and a survey. A FGD was conducted with the clinical pharmacists in two of the main government hospitals in Sudan. This was followed by an on-line survey among the clinical pharmacists of Sudan. Main outcome measure The role of the clinical pharmacists of Sudan and the challenges facing clinical pharmacy practice. Results Four pharmacists participated in the focus group and 51 out of 140 pharmacists (34\%) completed the on-line survey. The roles that were perceived by the majority of pharmacists as part of their duties in hospitals in Sudan were identifying drug-related problems $(100 \%, \mathrm{n}=51)$, providing drug-related information to healthcare professionals by $(96 \%, \mathrm{n}=47)$, and educating patients about their medicines $(96 \%, \mathrm{n}=48)$. The pharmacists identified a number of obstacles that hindered their progress in practice. These obstacles were related to the pharmacists themselves, the lack of senior clinical pharmacists for leadership, the environment they were
\end{abstract}

Hwaida Elsadig

hwaida.elsadig@bath.edu

University of Bath, Bath, UK

2 Cardiff University, Cardiff, UK

3 University of Helsinki, Helsinki, Finland working in and the training they had received in clinical pharmacy. Conclusion The new clinical pharmacists in Sudan faced several challenges that need to be overcome in order to move forward in their clinical practice. To do so they will require support from pharmacy educational institutions, other healthcare professionals and the healthcare institutions they are working within.

Keywords Pharamacist roles - Clinical pharmacy . Hospital pharmacy $\cdot$ Sudan

\section{Impacts on practice}

- The role of clinical pharmacy in Sudan needs to be acknowledged by the healthcare sector so that it can be further developed.

- Clinical pharmacists are amenable to the different duties associated with clinical pharmacy practice, and thus willing to provide effective patient care.

- For effective participation of clinical pharmacists in patient care, measures need to be taken to overcome the challenges and move forward with clinical pharmacy practice in Sudan.

\section{Introduction}

The use of the term 'clinical pharmacy' is thought to have flourished in the 1960s in association with pharmacy practice in hospital settings $[1,2]$. Since the emergence of the term in the sixties, different definitions have been considered but all have widely shared the concept of 'patient-oriented' pharmacy service [3]. In recent years different pharmacists' 
associations have provided different definitions for clinical pharmacy practice. For example, the term 'clinical pharmacy' was described by the International Federation of Pharmacists (FIP) as "-the work of pharmacists whose primary job is to interact with the healthcare system, interview and assess patients, make specific recommendations, monitor patient responses to drug therapy and provide medicine information" [4]. Another definition by the American College of Clinical Pharmacy (ACCP) is "-a health science discipline in which pharmacists provide patient care that optimizes medication therapy and promotes health, wellness and disease prevention. The practice of clinical pharmacy embraces the philosophy of pharmaceutical care; it blends a caring orientation with specialized therapeutic knowledge, experience, and judgement...." [5]. Other definitions for clinical pharmacy by different pharmacy bodies exist which raise the question if clinical pharmacy is a speciality linked to pharmacy practice in certain settings, is it complementing pharmacy practice or is it the change that pharmacy practice had to embrace [1, 2, 6, 7].

With regard to clinical pharmacy practice in hospitals, the role of pharmacists by the patient bedside has been argued to be the only way to maintain the pharmacy profession [8]. This move towards clinical roles in hospitals has enhanced the concept of professionalism in pharmacy $[9,10]$. A number of studies have examined the positive contribution of clinical pharmacists to patient care in hospitals [11-17]. Although the clinical role of pharmacists is well established in some countries, the defined practice of clinical pharmacy in hospitals is quite a new area for pharmacists in Sudan. The FIP Basel Statements on the future of hospital pharmacy discussed the vision of preparing and training hospital pharmacists to cover all areas of medicine use in the hospitals from procurement, preparation to clinical activities and involvement with prescribing [18]. Currently in Sudan where this study took place, clinical pharmacy in hospitals is considered a speciality which is only practised by pharmacists with a post graduate degree in clinical pharmacy.

Pharmacists have been working in hospitals in Sudan mainly in drug supply or doing managerial roles. These pharmacists constitute $49 \%$ of the pharmacists working in the public sector with the majority working in government hospitals [19]. The Federal Ministry of Health in Sudan, which is responsible for the development of national health policies and strategic plans, has acknowledged the need to develop pharmaceutical services in hospitals [20]. With the help of the Directorate of Pharmacy, a new policy regarding hospital pharmacy in Sudan was included in the pharmaceutical strategic plan for the period of 2005-2029. Different criteria were suggested in the plan to improve hospital pharmacy practice which included provision of a clinical pharmacy service by training more pharmacists to become clinical pharmacists.
The introduction of a Masters course in clinical pharmacy in the University of Khartoum more than 10 years ago led to the emergence of the new title of 'clinical pharmacist' in hospitals in Sudan. Accordingly, two different job classifications have been identified for hospital pharmacists in Khartoum hospitals during this study. These are clinical pharmacists, those with post graduate degree in clinical pharmacy, and non-clinical pharmacists. This study will focus on clinical pharmacists.

\section{Aim of the study}

The aim of this study was to examine the new practice of clinical pharmacy in Sudan and identify the challenges facing clinical pharmacists.

\section{Ethics approval}

Ethical approval for this study was obtained from the National Research Ethics Committee which is under the Federal Ministry of Health in Khartoum, Sudan.

\section{Methods}

This study was exploratory in nature and hence the participants were purposively selected. These were the pharmacists in Sudan who have a postgraduate degree in clinical pharmacy. A sequential exploratory mixed method design was used. This involved a focus group discussion (FGD) with the clinical pharmacists in two of the main government hospitals in Khartoum followed by an online survey among the clinical pharmacists of Sudan. One of the two hospitals was known to the researcher to have one of the first qualified clinical pharmacists who undertook the post graduate clinical pharmacy course in the University of Khartoum. The majority of the pharmacists in the hospitals were non-clinical pharmacists. Only five clinical pharmacists were identified in the two hospitals. The aim from the FGD was to provide the interaction between the participants which enriches the discussion [21]. The survey was meant to explore the issues discussed in the focus group with a larger population of clinical pharmacists.

The FGD was conducted by the first author in August 2012. An audio-recording was carried out after participants' permission was given. The FGD was conducted in a combination of the English and the Arabic language. The FGD was transcribed verbatim and any part in the Arabic language was then translated into the English language by the first author who was familiar with the language, dialect and culture of the participants. This closeness of researcher 
to those being researched enhances the validity of the findings [22-24]. The translation was validated with an independent pharmacist from Sudan.

For the survey, a list of the registered clinical pharmacists was obtained from the newly established Sudanese Society for Clinical Pharmacists (SSCP). The society had the e-mail addresses of 172 pharmacists in addition to the phone numbers of 109 clinical pharmacists. The decision was thus made to go for an on-line survey based on the e-mail addresses available. The survey was piloted for content and structure with four of the clinical pharmacists from the SSCP, and for possible technical issues with the research supervisors in University of Bath and University of Helsinki.

The questionnaire was designed using the University of Bristol Online Surveys (BOS) website, a free online survey tool available through the University of Bath. The questionnaire followed a 5-point Likert scale design. The survey questions were developed based on the data collected from the focus group discussion in addition to the literature review. E-mail invitations were sent to the pharmacists on the 20th of April 2014. This was followed by a phone message reminder for those pharmacists with phone numbers in addition to two e-mail reminders within two and four weeks of the survey launch.

\section{Data analysis}

The FGD was analysed by presenting a descriptive summary of the data followed by interpretation of the data in the discussion according to Krueger (1994) methods of analysis of FGD [25]. The analysis of the FGD was supported by the software N_vivo 9. The conversation was coded and then grouped under main themes derived from the participants' discussion or from the topic guide. For the survey the BOS website provided an initial descriptive analysis of the results. For further analyses, the data was transferred into SPSS statistics package version 20. Descriptive statistics were conducted using numbers and percentages to show the prevalence of the views obtained from the participants. The Mann-Whitney test was used to explore any differences in responses between the different groups of pharmacists based on gender and clinical hospital experience $(p<0.05)$.

\section{Results}

Of the five clinical pharmacists available in the two hospitals, four participated in the FGD. These pharmacists had different years of experience and were assigned to different specialities in the two hospitals as shown in Table 1. For the survey 24 e-mail addresses out of 172 sent came back as failed-delivery. Therefore, based on delivered e-mail addresses 51 pharmacists out of 148 (34\%) participated in the survey with 47 pharmacists completing all survey questions. There was participation from pharmacists with a wide range of years of practice based on their graduation year from pharmacy school (graduates from 1982 to 2010). The majority of pharmacists $(92 \%, \mathrm{n}=47)$ did their clinical pharmacy course in Sudan between the years 2007 and 2011. The remaining pharmacists obtained their clinical pharmacy post graduate degrees from universities in India, Malaysia or the UK. The survey participants' characteristics are summarized in Table 2. Although 12 (24\%) of the participating clinical pharmacists had no previous hospital experience, their views and perceptions of clinical pharmacy practice in Sudan was considered of relevance and hence they were included.

The main themes identified from the FGD were the postgraduate clinical pharmacy course, the pharmacists' new role and the barriers encountered in practice. In the survey the pharmacists were asked about their views of the current role of clinical pharmacists in Sudan and the perceived barriers to practice.

For the pharmacists to be appointed as clinical pharmacists they had to undertake a post graduate course in clinical pharmacy which took 2 years. When the pharmacists were asked about how they knew what they needed to do in hospitals as clinical pharmacists, they agreed that the clinical pharmacy course provided them with the introduction to their new role in addition to personal effort.

[...] from the course we became aware of what our role will be; in addition, the second year of the course was spent on the wards in S.... hospital... (Participant 2)

We benefited from the course, but there was also a personal effort. (Participant 3)

The pharmacists considered certain areas in which the clinical pharmacy course in Khartoum was lacking. One of these areas was the amount of time allocated to hospital training.

I think it [the course] should have been more practical than theory. (Participant 1)

The pharmacists also shared the view that even the hospital training had its limitations. For example, not having clinical pharmacists in the hospital was considered to be a setback in the course.

We were lost because there was no clinical pharmacist there. (Participant 2) 
Table 1 Characteristics of the participants in the Focus Group Discussion

\begin{tabular}{lllll}
\hline Participant code name & Sex & Hospital & $\begin{array}{l}\text { Country where Masters in clinical } \\
\text { pharmacy was obtained }\end{array}$ & $\begin{array}{l}\text { Years of practice as } \\
\text { clinical pharmacist }\end{array}$ \\
\hline Participant 1 & Female & Hospital 1 & Sudan & 2 \\
Participant 2 & Female & Hospital 2 & Sudan & 5 \\
Participant 3 & Female & Hospital 1 & Sudan & 4 \\
Participant 4 & Male & Hospital 2 & Malaysia & 4 \\
\hline
\end{tabular}

Table 2 Characteristics of the survey participants $(\mathrm{N}=51)$

\begin{tabular}{lcc}
\hline & $\begin{array}{c}\% \text { Of } \\
\text { participants }\end{array}$ & $\begin{array}{c}\text { Number of } \\
\text { participants }\end{array}$ \\
\hline Gender & & 15 \\
Male & 29 & 36 \\
Female & 71 & \\
Years since graduation & & 4 \\
$0-5$ & 9 & 14 \\
$6-10$ & 30 & 29 \\
$>10$ & 62 & 36 \\
Number of years since clinical pharmacy course & 13 \\
$0-5$ & 72 & 1 \\
6-10 & 26 & \\
$>10$ & 2 & 47 \\
Country where clinical pharmacy course was taken & \\
Sudan & 92 & 13 \\
Abroad & 8 & 26 \\
Currently hospital clinical pharmacist & 25 \\
Yes & 51 & \\
No & 49 & \\
Previous hospital experience & & \\
(for those who were not working in hospitals) & \\
Yes & 26 & \\
No & 24 & \\
\hline
\end{tabular}

The pharmacists had to accompany the doctors during their placement in the hospital. These doctors differed in their acceptance of the presence of the pharmacists and understanding of the requirements of their training, with some not understanding what a clinical pharmacist was supposed to do.

You just follow the doctor, he used to ask me, 'who are you?' [...], 'what do you want to do?' [...] I felt that I was lost [...]. (Participant1)

There was a doctor in the unit who said I don't want to see any pharmacist with me, [...] but on the other hand some doctors were cooperative. (Participant 2)

The pharmacists in the FGD considered that their practice in hospitals has changed after being appointed as clinical pharmacists. Although they had been working in their hospitals before taking their post graduate degree in clinical pharmacy, they were based mainly in the dispensary and had no ward duties.

A change has occurred to our job. Before, we didn't have any contact with the wards or the doctors. After the clinical course we started going to ward rounds, having contact with the patient [...] and with the doctors... (Participant 1)

In the survey, the majority of pharmacists considered that the different activities described for pharmacists were related to the role of the clinical pharmacists in hospitals in Sudan (Table 3). The main activities that the majority of pharmacists agreed with (either 'strongly agree' or 'agree) were for the clinical pharmacist to identify drug-related problems $(100 \%, \mathrm{n}=49)$, to provide drug-related information to healthcare professionals $96 \%$ (47) and to educate patients about their medicines $(96 \%, \mathrm{n}=48)$.

In the FGD the pharmacists considered the acceptance by doctors of their new role as one of the challenges facing their practice.

Although it has been four years since I started to be part of the ward rounds, the doctors don't think that I should be part of that and intervene and contribute to the treatment plan, as if all what I am doing is purely a voluntary work from my side, that is, an extra thing above of what is required from the pharmacist. (Participant 2)

The pharmacists also considered that the lack of easy access to information sources and absence of national guidelines was hindering their practice.

If you need any information about something, you want a book, internet; we have to pay from our own money'. (Participant 1)

There are no national guidelines; this part of the doctor's experience has got a big role in therapy [...], some doctors will tell you that the international guidelines belongs to foreign countries, it does not apply to us. (Participant 2)

Although the clinical pharmacists were appointed as specialist pharmacists, different to the other pharmacists in 
Table 3 Role of the clinical pharmacist in hospitals in Sudan $(\mathrm{N}=50)$

\begin{tabular}{|c|c|c|c|c|c|}
\hline & Strongly disagree $\%(\mathrm{~N})$ & Disagree & Neither agree nor disagree & Agree & $\begin{array}{l}\text { Strongly } \\
\text { agree }\end{array}$ \\
\hline Provide drug related information & $2(1)$ & $2(1)$ & - & $22(11)$ & $74(37)$ \\
\hline Educate patients about their medicines & - & - & $4(2)$ & $18(9)$ & $78(39)$ \\
\hline Identify drug related problems & - & - & - & $27(13)$ & $74(36)$ \\
\hline Assist doctors in prescribing drugs & - & $2(1)$ & $15(7)$ & $28(13)$ & $55(26)$ \\
\hline Provide drug related information mainly to doctors & $6(3)$ & $12(6)$ & $14(7)$ & $37(18)$ & $31(15)$ \\
\hline Inform doctors about availability of drugs & $2(1)$ & $8(4)$ & $10(5)$ & 39 (19) & $41(20)$ \\
\hline Inform doctors about therapy guidelines & - & $6(3)$ & $12(6)$ & $31(15)$ & $51(25)$ \\
\hline Take drug histories of patients admitted & - & $10(5)$ & $6(3)$ & $38(18)$ & $46(22)$ \\
\hline Inform doctors about cost effective medications & $2(1)$ & $4(2)$ & $20(10)$ & $38(19)$ & $28(14)$ \\
\hline Provide drug information mainly to patients & $8(4)$ & $14(7)$ & $12(6)$ & $38(19)$ & $28(14)$ \\
\hline Participate in clinical-care meetings & $2(1)$ & $2(1)$ & $4(2)$ & $35(17)$ & $57(28)$ \\
\hline Ensure prescribers are providing optimum therapy & - & $2(1)$ & $8(4)$ & $27(13)$ & $63(31)$ \\
\hline To be involved in doctors' choices of medicines & - & $8(4)$ & $14(7)$ & 24 (12) & $54(27)$ \\
\hline
\end{tabular}

- No participant chose this answer

the hospital, there was still no agreed job description for a clinical pharmacist.

Also one of the obstacles which may be clear from the beginning, is that there is no job description. (Participant 2)

Lack of enough clinical pharmacists in the hospitals also made it difficult for pharmacists to cover all patients as only one clinical pharmacist was appointed to each speciality.

We have got six units; it is difficult to cover the six.

(Participant 1)

The pharmacists were concerned that their managers were not aware of their need for continuous professional development (CPD) and although they gave them the chance to do the clinical pharmacy course, this was not enough and further support was required.

We just started knowing how to practice clinical pharmacy, but there is no support for continuous training. (Participant 4)

In the survey that followed the pharmacists either agreed or strongly agreed that the main barriers affecting clinical pharmacy practice were the lack of experience in applying the clinical knowledge acquired to practice $(94 \%, \mathrm{n}=46)$, the unavailability of senior clinical pharmacists $(90 \%$, $\mathrm{n}=43$ ) and the lack of opportunities for continuous professional development $(98 \%, \mathrm{n}=46)$. The details of these results are shown in Table 4.

In the survey $68 \%$ (34) of pharmacists did not consider that limited support from doctors to be an obstacle for clinical pharmacists. However, 59\% (27) considered that there was resistance from doctors to pharmacists' involvement in prescribing.

There was a split between pharmacists' views with regard to pharmacists themselves being resistant to change. While $48 \%$ (24) found this not to be true, $40 \%$ (20) were in agreement with this statement. A large number of pharmacists $65 \%$ (31) either 'agreed' or 'strongly agreed' that lack of confidence is affecting clinical pharmacy practice.

The absence of national guidelines as mentioned by one of the participants in the FGD was perceived by $80 \%$ (37) of the pharmacists as affecting their practice. In addition, $40 \%$ (19) of pharmacists felt that the use of international guidelines by prescribers as a barrier to their practice.

Using the Mann-Whitney test, a statistically significant difference in response was found between participants with regard to whether or not they had previous hospital clinical experience. Pharmacists with hospital clinical experience were more likely to agree than those with no clinical experience that there were not enough clinical pharmacists in hospitals $(\mathrm{U}=136, p=0.037)$. Furthermore, male pharmacists were more likely to agree than females that a lack of confidence from pharmacists was creating a barrier to practice $(\mathrm{U}=104, p=0.001)$.

\section{Discussion}

This mixed method study which was conducted within a period of 2 years from August 2012 to April 2014 investigated the new practice of clinical pharmacy in Sudan. The study found that hospital pharmacists felt a shift has 
Table 4 Barriers affecting clinical pharmacy practice in hospitals in Sudan $(\mathrm{N}=50)$

\begin{tabular}{|c|c|c|c|c|c|}
\hline Statement & $\begin{array}{l}\text { Strongly } \\
\text { disagree\% (N) }\end{array}$ & $\begin{array}{l}\text { Disagree\% } \\
(\mathrm{N})\end{array}$ & $\begin{array}{l}\text { Neither agree nor } \\
\text { disagree\% }(\mathrm{N})\end{array}$ & $\begin{array}{l}\text { Agree\% } \\
(\mathrm{N})\end{array}$ & $\begin{array}{l}\text { Strongly } \\
\text { agree\% }(\mathrm{N})\end{array}$ \\
\hline Lack of information sources & $12(6)$ & $20(10)$ & $10(5)$ & $40(20)$ & $18(9)$ \\
\hline Pharmacists' resistance to change & $18(9)$ & $30(15)$ & $12(6)$ & $30(15)$ & $10(5)$ \\
\hline Limited support from doctors & $32(16)$ & $36(18)$ & $14(7)$ & $12(6)$ & $6(3)$ \\
\hline Lack of confidence & $2(1)$ & $15(7)$ & $19(9)$ & $46(22)$ & $19(9)$ \\
\hline Hospital payment & $4(2)$ & $20(10)$ & $6(3)$ & $32(16)$ & $38(19)$ \\
\hline Doctors following 'international' guidelines & $2(1)$ & $21(10)$ & $38(18)$ & $38(18)$ & $2(1)$ \\
\hline Unavailability of 'national' guidelines & - & $11(5)$ & $9(4)$ & $52(24)$ & $28(13)$ \\
\hline Lack of experience of applying clinical knowledge to practice & $2(1)$ & $4(2)$ & - & $47(23)$ & $47(23)$ \\
\hline More concern with doctors' approval than performing the job & $4(2)$ & $21(10)$ & $15(7)$ & $46(22)$ & $15(7)$ \\
\hline Resistance from doctors to pharmacists involvement in prescribing & $4(2)$ & $20(9)$ & $17(8)$ & $35(16)$ & $24(11)$ \\
\hline Lack of CPD opportunities & - & $2(1)$ & - & 40 (19) & $57(27)$ \\
\hline No senior clinical pharmacists & $2(1)$ & $2(1)$ & $6(3)$ & $23(11)$ & $67(32)$ \\
\hline No job description for 'clinical pharmacist' & $4(2)$ & $6(3)$ & $6(3)$ & $45(21)$ & $38(18)$ \\
\hline Lack of communication skills & $8(4)$ & $35(17)$ & $17(8)$ & $38(18)$ & $2(1)$ \\
\hline Not enough clinical pharmacists in the hospital & $2(1)$ & $4(2)$ & $6(3)$ & $43(21)$ & $45(22)$ \\
\hline
\end{tabular}

- No participant chose this answer

occurred in their professional status since they became clinical pharmacists but there are a number of challenges facing clinical pharmacy practice.

The majority of pharmacists when presented with different duties related to clinical pharmacy practice expected clinical pharmacists in hospitals in Sudan to be performing most of these duties. There were roles which achieved an overall agreement by pharmacists as being part of the clinical pharmacist's job. These were identifying drug related problems $(100 \%, \mathrm{n}=49)$ and educating patients about their medicines $(96 \%, \mathrm{n}=48)$. There was also a wide acceptance from pharmacists that their role in hospitals involved participation with prescribers in providing optimum therapy.

With regard to the barriers facing pharmacists, these can be divided into two groups. The first group was about pharmacists themselves being the barrier to role change. Some of the pharmacists perceived that personal characteristics such as a lack of confidence $(65 \%, \mathrm{n}=31)$ and an attitude which is resistant to change $(40 \%, \mathrm{n}=20)$ as challenges to clinical pharmacy practice. The argument that pharmacists' attitudes have prevented them from making role changes was previously discussed [26-28]. The claim was that the key constraint to the advancement of clinical pharmacy practice was due to more than just external factors such as resistance from the doctors or lack of enough pharmacists. The main obstacle was seen to be the pharmacy culture itself which is resistant in shifting from the 'comfortable zone' of drug focused practice to the 'unknowns' of the patient centred practice. However, the expectation is that as more skills are acquired, pharmacists in Sudan will be able to overcome these personal barriers.

The second group of barriers included external factors such as not having senior clinical pharmacists or having prescribers resistant to pharmacist involvement. Interestingly $68 \%(n=34)$ of the pharmacists in this survey did not perceive the lack of support from doctors as a barrier to practice. Whether this means that the doctors were supporting them or their support was not required is unknown. However, more than half of the participants $(59 \%, \mathrm{n}=27)$ considered that doctors' resistance to pharmacists getting involved in prescribing as a challenge to clinical pharmacy practice. This resonates with previous findings that prescribers may be less comfortable with advanced roles for pharmacists such as recommending prescription drugs [29-33].

The lack of senior clinical pharmacists in hospitals who can support new clinical pharmacists was seen as one of the major challenges in practice. Being a new area of practice in Sudan, current clinical pharmacists need to consider themselves as the leaders of the new practice, especially as a large number of those who did the clinical pharmacy course had previous hospital work experience. The leaders of clinical pharmacy practice around the world have been pharmacists who were working in hospitals but made the shift from being pharmacy based to being available on the wards [1, 34].

The pharmacists were also challenged by the absence of national guidelines and the lack of access to information. In a study in Jordan, limited access to information sources 
was identified by pharmacists as making them less able of ensuring evidence-based prescribing [35]. Furthermore, the pharmacists felt that the lack of continuous professional development was hindering their practice. Despite limited resources pharmacists may need to take the initiative themselves and find suitable ways to undertake CPD. It is hoped that the recent efforts by the SSCP to organize training sessions in different areas of clinical care may be a starting point for pharmacists for professional development. However, the Society needs to consider that pharmacists not only require more clinical knowledge but also need to develop certain skills for example communication skills in order to be able to transfer their clinical knowledge to practice.

The survey found that half of the participants who were clinical pharmacists were not actually working in hospitals. The actual cause for that is unknown but one reason may be that the rate of pay in hospitals, which was perceived as a barrier to clinical pharmacy practice, was low and hence pharmacists felt that their qualification was unrewarded. Furthermore, there may not be enough 'clinical pharmacist' jobs compared to non-clinical jobs in hospitals. It may also be a personal decision from the pharmacists that although they acquired the clinical post-graduate degree, they do not necessarily link that with hospital work.

There are currently two tiers of pharmacists in Sudan, clinical and non-clinical pharmacists. Only clinical pharmacists are expected to have ward duties. The concern regarding two tiers of pharmacists was previously raised in that it allows different levels of services to be provided by pharmacists [36]. This can create confusion among the public and healthcare professionals about what service to expect from pharmacists which is not in favour of the profession. However, the undergraduate pharmacy courses in Sudan were perceived as not providing the required clinical training [37]. Some of the participating pharmacists identified the need for a less theoretical and more clinical approach to pharmacists' training. The latter has been discussed in previous studies where the emphasis on a change in pharmacy teaching was perceived to be the main element in creating competent pharmacists $[1,2,9,10]$.

It has been argued that pharmacists alone cannot advance without the support of the government and the healthcare institutions in which they are practicing [2, 38, 39]. This support whether in the form of training or availability of resources was considered by some of the pharmacists in this study to be a requirement for progress. The Federal Ministry of Health in Sudan supported the call for improvement of hospital pharmaceutical services to meet future challenges [20]. However, as pharmacy is only one issue out of many concerns facing the healthcare system, it may be a while before the health authorities will have the resources to put into clinical pharmacy practice in Sudan.
The pharmacists in this study perceived that their practice was affected by a lack of a job description. Although the majority of the pharmacists seemed to agree with the different roles identified for hospital clinical pharmacists, one can understand the uncertainty these pharmacists were facing in deciding to what extent this new 'clinical' identity would allow them to intervene in patient management. Considering the changes that are either advocated for pharmacy practice or those which have already taken place, there is a need to identify the exact role of the pharmacist of today [40]. The argument is that unless the exact role of the pharmacist is acknowledged, pharmacists will struggle to get the recognition for their new clinical identity. However, the assumption that there is a one model for clinical pharmacy practice that fits all may be far from realistic. Although some pharmacy bodies in different countries especially those with advanced clinical pharmacy practice may have set descriptions and standards for clinical practice, these may not fit with the practice in Sudan. There is no doubt that there is a need for standards for practice. However, clinical pharmacists together with pharmacy regulating bodies in Sudan need to set the standards and the job specification for practice that suit the patient and the healthcare system of the country.

As with all studies using self-report it is not known whether the actual responses reflect the true behaviour of the participants. Measures such as anonymity and confidentiality were used to minimize effects like social-desirability bias. The findings were based on the results obtained from the pharmacists who responded to the questionnaire. It is not known if those who did not respond would have a different perspective of the issues explored in the survey.

\section{Conclusion}

The practice of clinical pharmacy in hospitals in Sudan can be considered to be in its preliminary stages of development. Clinical pharmacists in Sudan have experienced barriers in their practice that they need to overcome in order that patients can benefit from their pharmacotherapy knowledge. It is also of importance that for clinical pharmacists to take their desired professional place, pharmacy academics, healthcare professionals as well as healthcare mangers, need to be involved to support the transition.

Acknowledgements The authors would like to thank all the pharmacists who voluntarily participated in this study.

Funding This study was part of a $\mathrm{PhD}$ scholarship from the University of Bath. The authors would like to thank the Gordon Memorial College for its financial support.

Conflicts of interest None. 


\section{References}

1. McLeod DC. Clinical pharmacy: the past, present and future. Am J Hosp Pharm. 1976;33(1):29-38.

2. Hepler CD, Strand LM. Opportunities and responsibilities in pharmaceutical care. Am J Hosp Pharm. 1990;47(3):533-43.

3. Francke GN. Evolvement of Clinical Pharmacy. Drug Intell Clin Pharm. 1969;3:348-54.

4. Weidenmayer K, Summers RS, Mackie CA, Gous AGS, Everard M, Tromp D. Developing pharmacy practice FIP, WHO.pdf; 2006.

5. American College of clinical Pharmacy. The definition of clinical pharmacy. Pharmacotherpay. 2008;28(6):816-7.

6. Hepler CD. Pharmacy as a clinical profession. Am J Hosp Pharm. 1985;42(6):1298-306.

7. Smith WE. Clinical pharmacy: reflections and forecasts. Ann Pharmacother. 2007;41(2):325-8.

8. Anderson RD. The peril of deprofessionalization. Am J HealthSyst Pharm. 2004;61:2373-9.

9. Hammer DP. Professional attitudes and behaviors: the "A's and B's” of professionalism. Am J Pharm Educ. 2000;64(4):455-64.

10. Schafheutle EI, Hassell K, Ashcroft DM, Harrison S. Organizational philosophy as a new perspective on understanding the learning of professionalism. Am J Pharm Educ. 2013;77(10):214.

11. Dale MA, Coopeland R, Barton R. Prescribing errors on medical wards and the impactof clinical pharmacists. Int $\mathrm{J}$ Pharm Pract. 2003;11(1):19-24.

12. Bond CA, Raehl CL, Franke T. Interrelationships among mortality rates, drug costs, total cost of care, and length of stay in United States hospitals: summary and recommendations for clinical pharmacy services and staffing. Pharmacotherapy. 2001;21(2):129-41.

13. Boyko WL Jr, Yurkowski PJ, Ivey MF, Armitstead JA, Roberts BL. Pharmacist influence on economic and morbidity outcomes in a tertiary care teaching hospital. Am J Health Syst Pharm. 1997;54(14):1591-5.

14. Horning KK, Hoehns JD, Doucette WR. Adherence to clinical practice guidelines for 7 chronic conditions in long-term-care patients who received pharmacist disease management services versus traditional drug regimen review. J Manag Care Pharm. 2007;13(1):28-36.

15. Howard RL, Avery AJ, Howard PD, Partridge M. Investigation into the reasons for preventable drug related admissions to a medical admissions unit: observational study. Qual Saf Health Care. 2003;12(4):280-5.

16. Leape LL, Cullen DJ, Clapp MD, Burdick E, Demonaco HJ, Erickson JI, et al. Pharmacist participation on physician rounds and adverse drug events in the intensive care unit. JAMA. 1999;282(3):267-70.

17. Miller G, Franklin BD, Jacklin A. Including pharmacists on consultant-led ward rounds: a prospective non-randomised controlled trial. Clin Med J R Coll Phys. 2011;11(4):312-6.

18. Revised FIP Basel Statements on the future of hospital pharmacists. 2015 Cited 10 June 2017. http://apps.who.int/medicinedocs/ en/d/Js22090en/.

19. Directorate of Pharmacy MoH, Sudan. Pharmacy Statistics Report. 2007.

20. Directorate of Pharmacy MoH, Sudan Policy of Hospital Pharmacy 2006 (cited 4 Oct 2010). www.pharmacy.gov.sd. Accessed 20 Aug 2012.
21. Smith F. Research methods in pharmacy practice. London: Pharmaceutical Press; 2002. p. 144.

22. Al-Amer R, Ramjan L, Glew P, Darwish M, Salamonson Y. Language translation challenges with Arabic speakers participating in qualitative research studies. Int $\mathrm{J}$ Nurs Stud. 2016;54:150-7.

23. Choi J, Kushner KE, Mill J, Lai DW. Understanding the language, the culture, and the experience: translation in cross-cultural research. Int J Qual Methods. 2012;11(5):652-65.

24. Esposito N. From meaning to meaning: the influence of translation techniques on non-English focus group research. Qual Health Res. 2001;11(4):568-79.

25. Krueger RA. Focus groups: a practical guide for applied research. 2nd ed. Thousand Oaks: Sage; 1994. p. 255.

26. Al Hamarneh YN, Rosenthal M, McElnay JC, Tsuyuki RT. Pharmacists' perceptions of their professional role: insights into hospital pharmacy culture. Can J Hosp Pharm. 2011;64(1):31-5.

27. Hall J, Rosenthal M, Family H, Sutton J, Hall K, Tsuyuki RT. Personality traits of hospital pharmacists: toward a better understanding of factors influencing pharmacy practice change. Can J Hosp Pharm. 2013;66(5):289-95.

28. Rosenthal M, Austin Zubin, Tsuyuki Ross T. Are pharmacists the ultimate barrier to pharmacy practice change? Can Pharm J/Revue des Pharmaciens du Canada. 2010;143(1):37-42.

29. Awad A, Matowe L, Capps P. Medical doctors' perceptions and expectations of the role of hospital pharmacists in Sudan. Pharm World Sci. 2007;29:557-64.

30. Matowe L, Abahussain EA, Al-Saffar N, Bihzad SM, Al-Foraih A, Al-Kandery AA. Physicians' perceptions and expectations of pharmacists' professional duties in government hospitals in Kuwait. Med Princ Pract. 2006;15(3):185-9.

31. Smith WE, Ray MD, Shannon DM. Physicians' expectations of pharmacists. Am J Health Syst Pharm. 2002;59(1):50-7.

32. Tahaineh LM, Wazaify M, Albsoul-Younes A, Khader Y, Zaidan M. Perceptions, experiences, and expectations of physicians in hospital settings in Jordan regarding the role of the pharmacist. Res Soc Adm Pharm: RSAP. 2009;5(1):63-70.

33. Zaidan M, Singh R, Wazaify M, Tahaineh L. Physicians' perceptions, expectations, and experience with pharmacists at Hamad Medical Corporation in Qatar. J Multidiscip Healthcare. 2011;4:85-90.

34. Cousins DH, Luscombe DK. Forces for change and the evolution of clinical pharmacy practice. Pharm J. 1995;255:771-6.

35. Abu Farha R, Alefishat E, Suyagh M, Elayeh E, Mayyas A. Evidence-based medicine use in pharmacy practice: a cross-sectional survey. J Eval Clin Pract. 2014;. doi:10.1111/jep.12212.

36. Provost GP. Clinical pharmacy-speciality or general direction? Drug Intell Clin Pharm. 1972;6(8):285.

37. Mohamed SS. Current state of pharmacy education in the Sudan. Am J Pharm Educ. 2011;75(4):65a.

38. Phillips JO, Strand LM, Chesteen SA, Morley PC. Functional and structural prerequisites for clinical pharmacy services. Am J Hosp Pharm. 1987;44(7):1598-605.

39. Penm J, Moles R, Wang H, Li Y, Chaar B. Factors affecting the implementation of clinical pharmacy services in China. Qual Health Res. 2014;24(3):345-56.

40. Elvey R, Hassell K, Hall J. Who do you think you are? Pharmacists' perceptions of their professional identity. Int $\mathrm{J}$ Pharm Pract. 2013;21(5):322-32. 